\title{
Biliary stent migration presenting as a recurrent pilonidal abscess with underlying rectocutaneous fistula
}

A 53-year-old patient was admitted to the gastroenterology department for the management of a benign biliary stricture secondary to chronic alcoholic pancreatitis. He underwent sphincterotomy and placement of a $10 \mathrm{Fr} \times 10 \mathrm{~cm}$ plastic biliary stent. Endoscopic follow-up 2 months later revealed spontaneous migration of the stent and no further intervention was performed.

The patient was admitted to the general surgery outpatient clinic 7 years later for the management of a recurrent pilonidal abscess. Excision of the abscess revealed a long fistulous track towards the coccyx with a plastic stent inside it ( Fig. 1 a, b); the findings indicated a rectocutaneous fistula secondary to biliary stent migration. In addition, computed tomography scan showed a 1-cm defect of the sacrococcygeal junction in contact with the rectum ( Fig.2). Postoperatively, the patient was treated with antibiotics and vacuum-assisted closure therapy and went on to make an excellent recovery. His follow-up over 4 years was unremarkable.

Complications of stent placement are well known and include migration with fistula formation between a variety of organs, such as: duodenocolic fistula [1], duodenoscrotal fistula [2], enterosplenic fistula [3], enterocutaneous fistula [4], and colovaginal fistula [5]. However, to the best of our knowledge recurrent abscess secondary to a rectocutaneous fistula has not been described previously.

Endoscopy_UCTN_Code_CPL_1AK_2AI

Competing interests: None

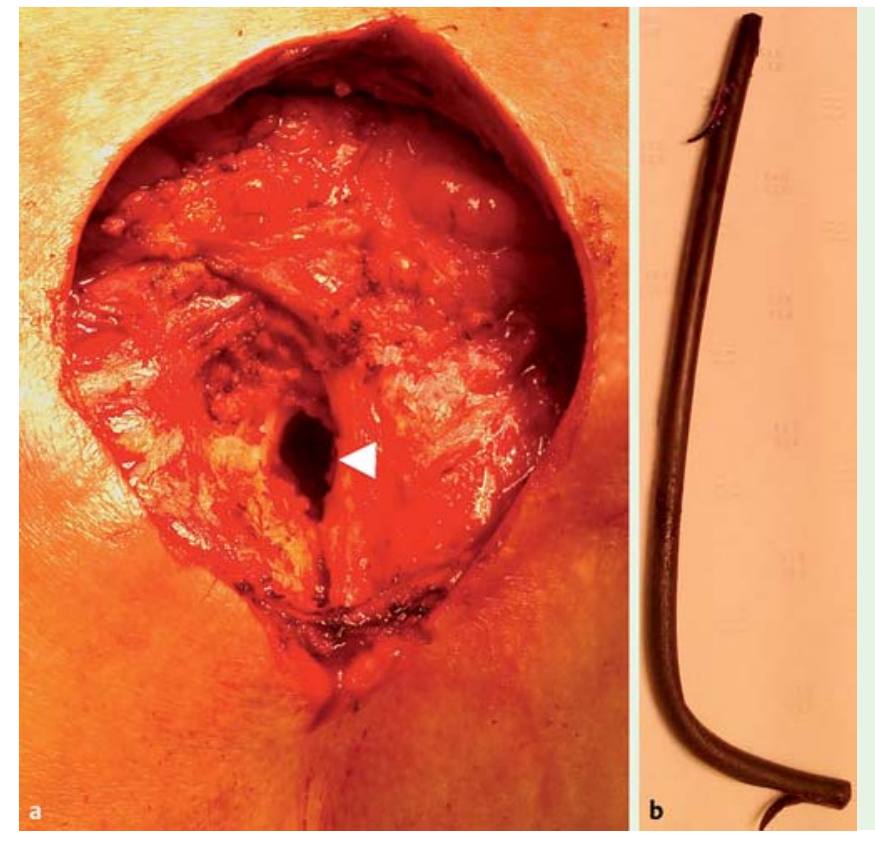

Fig. 1 The patient was admitted for management of a recurrent pilonidal abscess. a Excision of the pilonidal abscess revealed a fistulous track (arrowhead). $\mathbf{b} \mathrm{A} 10 \mathrm{Fr} \times 10 \mathrm{~cm}$ plastic biliary stent was retrieved from the fistula.

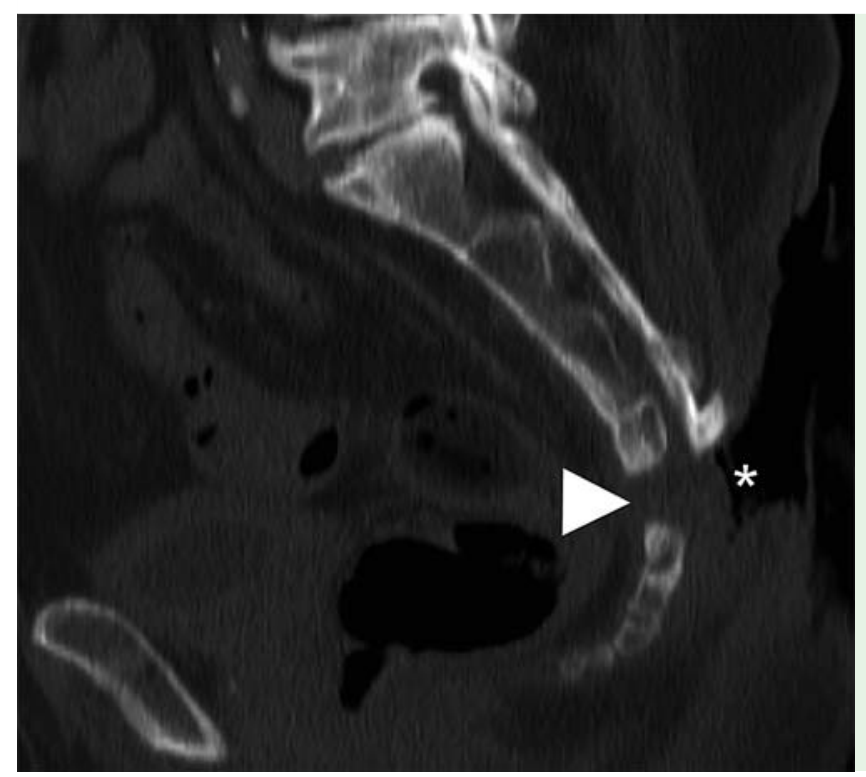

Fig. 2 Postoperative computed tomography scan disclosed a $1-\mathrm{cm}$ bone defect of the sacrococcygeal junction (arrowhead) in contact with the posterior wall of the rectum. The asterisk indicates the site of excision of the abscess. 


\section{G. Mavrogenis ${ }^{1}$, M. Lalot ${ }^{2}$, Y. Hoebeke ${ }^{3}$, P. Warzée ${ }^{1}$, P. Van Ende ${ }^{2}$, A. Sibille ${ }^{1}$}

${ }^{1}$ Department of Gastroenterology, Site Notre Dame, Grand Hôpital de Charleroi, Charleroi, Belgium

2 Department of Anesthesiology, Site Notre Dame, Grand Hôpital de Charleroi, Charleroi, Belgium

${ }^{3}$ Department of General Surgery, Site Notre Dame, Grand Hôpital de Charleroi, Charleroi, Belgium

\section{References}

1 Ang BK, Wee SB, Kaushik SP et al. Duodenalcolic fistula resulting from migration of a biliary stent: a case report. Gastrointest Endosc 1998; 48: 80-83

2 Basile A, Macri' A, Lamberto S et al. Duodenoscrotal fistula secondary to retroperitoneal migration of an endoscopically placed plastic biliary stent. Gastrointest Endosc 2003; 57: $136-138$

3 Baccarani U, Risaliti A, Sainz-Barriga $M$ et al. Ileosplenic fistula and splenic abscesses caused by migration of biliary stents in a liver transplant recipient. Gastrointest Endosc 2003; 58: $811-813$

4 Karim A, Orbell JH, Bhatti K et al. Biliary stent migration presenting as a recurrent abdominal wall abscess with underlying enterocutaneous fistula. Gastrointest Endosc 2006; 63: $874-876$

5 Blake AM, Monga N, Dunn EM. Biliary stent causing colovaginal fistula: case report. JSLS 2004; 8 : 73-75
Bibliography

Dol http://dx.doi.org/

10.1055/s-0033-1344413

Endoscopy 2013; 45: E301-E302

(c) Georg Thieme Verlag KG

Stuttgart · New York

ISSN 0013-726X

\section{Corresponding author}

\section{G. Mavrogenis, MD}

Grand Hôpital de Charleroi

Site Notre Dame

3 Grand Rue

Charleroi 6000

\section{Belgium}

Fax: +32-71-102779

mavrogenis@gmail.com 